\title{
Seasonal variation of water uptake of a Quercus suber tree in Central Portugal
}

\author{
Nadezhda Nadezhdina • Maria Isabel Ferreira • \\ Rodolfo Silva • Carlos Arruda Pacheco
}

Received: 7 February 2007 / Accepted: 15 August 2007 /Published online: 13 September 2007

(C) Springer Science + Business Media B.V. 2007

\begin{abstract}
Hydraulic redistribution (HR) is the phenomenon where plant roots transfer water between soil horizons of different water potential. When dry soil is a stronger sink for water loss from the plant than transpiration, water absorbed by roots in wetter soil horizons is transferred toward, and exuded into dry soil via flow reversals through the roots. Reverse flow is a good marker of HR and can serve as a useful tool to study it over the long-term. Seasonal variation of water uptake of a Quercus suber tree was studied from late winter through autumn 2003 at Rio Frio near Lisbon, Portugal. Sap flow was measured in five small shallow roots (diameter of 3-4 cm), 1 to $2 \mathrm{~m}$ from the tree trunk and in four azimuths and at different xylem depths at the trunk base, using the heat field deformation method (HFD). The pattern of sap flow differed among lateral roots as soil dried
\end{abstract}

Responsible Editor: Stephen S.O. Burgess.

N. Nadezhdina $(\square)$

Institute of Forest Ecology,

Mendel University of Agriculture and Forestry,

Zemedelska 3,

61300 Brno, Czech Republic

e-mail: nadezdan@mendelu.cz

M. I. Ferreira $\cdot$ R. Silva $\cdot$ C. A. Pacheco

Agricultural Eng Department and Environmental Sciences

Department, Instituto Superior de Agronomia - ISA,

Technical University of Lisbon (UTL),

Tapada da Ajuda,

1349017 Lisbon, Portugal with constant positive flow in three roots and reverse flow in two other roots during the night when transpiration ceased. Rain modified the pattern of flow in these two roots by eliminating reverse flow and substantially increasing water uptake for transpiration during the day. The increase in water uptake in three other roots following rain was not so substantial. In addition, the flux in individual roots was correlated to different degrees with the flux at different radial depths and azimuthal directions in trunk xylem. The flow in outer trunk xylem seemed to be mostly consistent with water movement from surface soil horizons, whereas deep roots seemed to supply water to the whole cross-section of sapwood. When water flow substantially decreased in shallow lateral roots and the outer stem xylem during drought, water flow in the inner sapwood was maintained, presumably due to its direct connection to deep roots. Results also suggest the importance of the sap flow sensor placement, in relation to sinker roots, as to whether lateral roots might be found to exhibit reverse flow during drought. This study is consistent with the dimorphic rooting habit of Quercus suber trees in which deep roots access groundwater to supply superficial roots and the whole tree, when shallow soil layers were dry.

Keywords Heat field deformation method .

Hydraulic lift · Mediterranean · Multi-point sensors ·

Sap flow $\cdot$ Seasonal dynamics .

Sensor placement in roots $\cdot$ Soil water 


\section{Introduction}

Hydraulic redistribution in soil (HR) in response to gradients of water potential is important for trees exposed to long periods of drought. Different types of hydraulic redistribution have been reported: vertical upward transfer of water (hydraulic lift, HL) from deep to more dry shallow soil layers (Richards and Caldwell 1987; Dawson 1993; Dawson and Pate 1996; Caldwell et al. 1998; Horton and Hart 1998), downward transport or inverse hydraulic lift, (Schulze et al. 1998; Smith et al. 1999; Burgess et al. 1998, 2001a), and horizontal redistribution of water via relatively superficial lateral roots (Brooks et al. 2002). Some authors have reported that hydraulic redistribution could increase stand transpiration in some days by over $20 \%$ (Ryel et al. 2002), while others conclude that it probably had a small, if any direct influence on whole plant transpiration (Hultine et al. 2003). In general, HR is likely to have significant ecological benefits for plants (Caldwell et al. 1998; Emerman 1996; Dawson and Pate 1996; Jackson et al. 2000; Domec et al. 2004).

Not much is known about mechanisms of water uptake by trees in non-irrigated stands growing in a Mediterranean climate in Europe (such as olive or cork oak plantations). However, these species are extremely important to the ecology and sustainability of the systems (MADRP 2000). Quercus suber grows at latitudes around $40^{\circ}$ mainly in the south-west of Europe and the extreme north-west of Africa where, during summer, the air humidity is relatively high (in relation to areas with similar latitudes). According to Ribeiro and Tomé (2002) the actual area of cork oak in Portugal is $7100 \mathrm{~km}^{2}$ which represents $33 \%$ of the total cork oak area in the world and $22 \%$ of the total forested area in Portugal. Quercus suber has a dimorphic root system (Jackson et al. 1999) and potential access to deep water. Therefore, it has the potential for HR, which may be an important hydrological process in the Mediterranean ecosystem. Evidence for hydraulic lift by cork oak trees in Portugal was well documented recently by KurzBesson et al. (2006) using stable isotope analyses and soil water potential measurements near the surface. These authors estimated a significant contribution of HL by cork oak trees to the local water balance with HL accounting for $17-81 \%$ of the water used during the following day by tree transpiration at the peak of the drought season. However, HR and water transport pathways in a cork oak are still poorly understood. An opportunity to observe $Q$. suber root architecture was offered when a large part of the root system of a tree was exposed to a depth of around $6 \mathrm{~m}$ by accidental flooding (Fig. 1). A species with such a root system is a good model to study HR.

We believe sap flow measurement is the best method to study HR. However, due to methodological difficulties, there have not been many studies on this type and the majority of the information about HR in soil has been gathered from measurements of soil water potential, application of stable isotopes and daily soil moisture variations (Caldwell and Richards 1989; Dawson 1993; Brooks et al. 2002, 2006; Warren et al. 2005). Most authors investigating HR with sap flow techniques have used either constant heat balance (Sakuratani 1981; Lott et al. 1996; Smith et al. 1999) or heat pulse techniques (Huber 1932; Moreno et al. 1996; Green et al. 1997, 2003; Fernandez et al. 2001). Since the modified heat pulse velocity method (Marshall 1958) - heat ratio method, HRM - was first applied by Burgess et al. (1998, 2001a) for root studies, investigations of water redistribution in soil via roots have developed substantially (Burgess et al. 1998, 2000a, b, 2001b; Scholz et al. 2002; Moreira et al. 2003; Hultine et al. 2003). The modified thermal dissipation technique for bi-directional flow measurements in roots has also been used (Brooks et al. 2002, 2006).

Our understanding of water transport pathways in the plant associated with HR is still quite limited, particularly connections between root and trunk xylem, Comparable measurements of sap flow in roots and stem to demonstrate root behaviour in relation to water transport in the stem were conducted by Fernandez et al. (2001) and Scholz et al. (2002). Hultine et al. (2003) estimated the time lag between the stem and root sap flow during morning hours in trees in a Chihuahuan desert. More recently Burgess and Bleby (2006) directly linked root sap flow with stem sap flow of eucalyptus trees. The authors found that large axial flows in the outer stem xylem are associated with the horizontal transfer of water between roots on opposite sides of the stem. Our earlier results (Nadezhdina and Cermak 2000a, b, 2003; Nadezhdina et al. 2002) suggest that the outer trunk xylem is primarily connected with superficial roots whereas deep roots influenced paths of water 
Fig. 1 Example of a cork oak root system accidentally exposed after bank collapsing during a flood. Numerous very long surface roots are well visible in the soil layer of $0.5-0.8 \mathrm{~m}$. There are also several sinkers visible extending to soil depths deeper than $5 \mathrm{~m}$

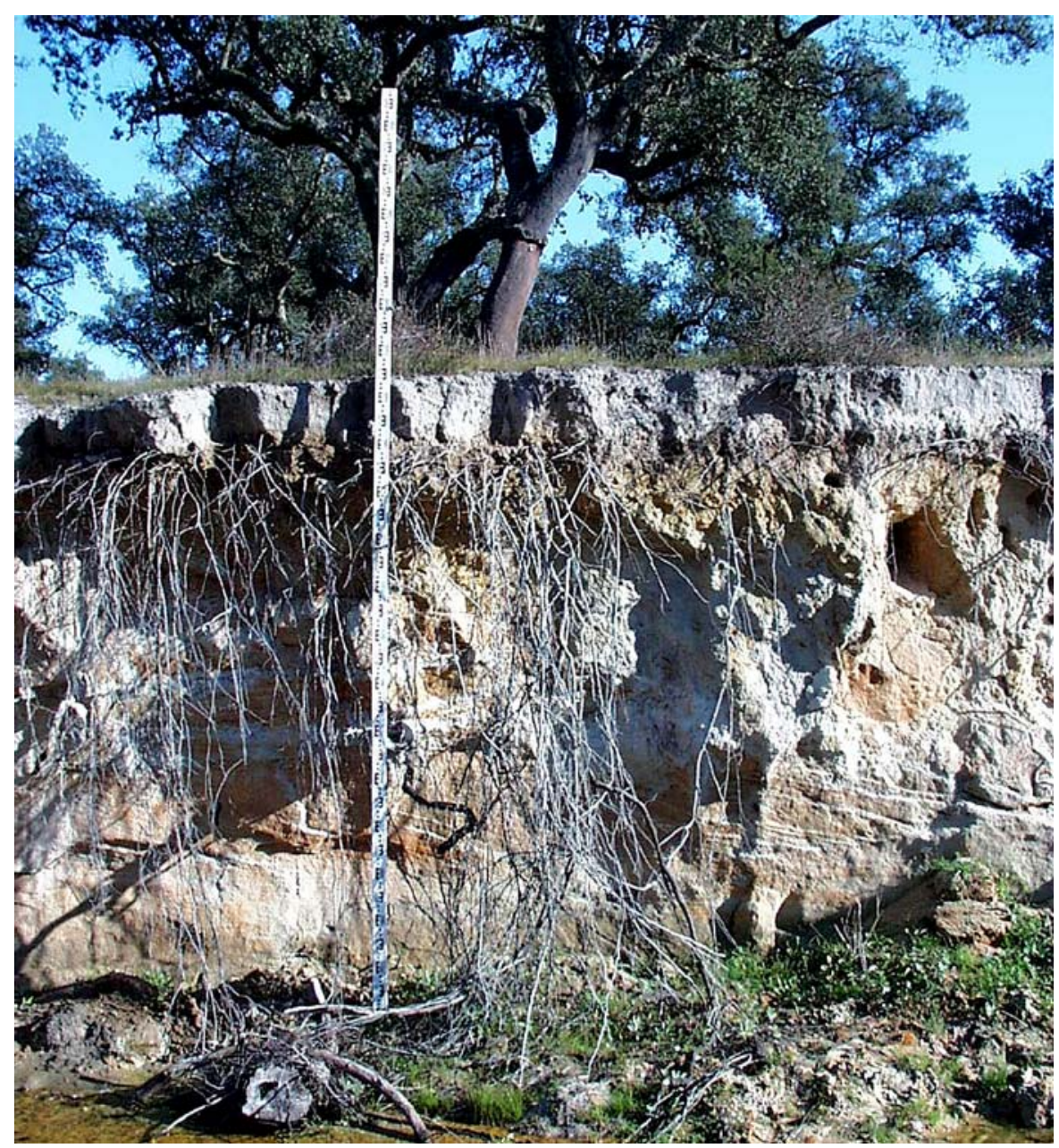

through the whole stem xylem. Thus, it is logical to expect that trunk xylem layers may respond differently to soil drying.

The main goal of this study was to study water uptake of Quercus suber as a good model tree for better understanding of HR in this Mediterranean ecosystem. We also wanted to investigate the link between surface and deep root sap flow with sap flow in the outer and the inner trunk xylem. We measured sap flow in lateral roots with and without sinkers attached downstream to the point of sensor installation, and hypothesized that shallow lateral root (no sinkers) sap flow would be strongly correlated with sap flow measured in the outer trunk xylem. Using sap flow in lateral roots with sinkers as an indirect indication of sap flow in deep roots, we hypothesized that sap flow in deep roots would be correlated with sap flow measured in the whole trunk xylem.

\section{Materials and methods}

Site characteristics, meteorological and soil water variables

The field plot (4,100 ha of montado) is located in the low Tagus river basin, between Lisbon and Setúbal $\left(38^{\circ} 38^{\prime} \mathrm{N}, 8^{\circ} 51^{\prime} \mathrm{W}, 30 \mathrm{~m}\right)$. The climate is Mediterranean with Atlantic influence, with $750 \mathrm{~mm}$ and $16^{\circ} \mathrm{C}$ of annual average precipitation and temperature. The plantation of Quercus suber trees is over 80 years old, with spacing of $10 \times 11 \mathrm{~m}$, density of 66 trees/ha in 2003, and average height of 10 to $12 \mathrm{~m}$.

The almost flat landscape is lithologically characterized by coarse and loamy sandstone facies in the top of the Pliocenic formations with more than $100 \mathrm{~m}$ thickness (Tavares and Oliveira 2001). The sandstone layers, with ferruginous cement alternated with clay 
layers, give this system the characteristic of an aquifer with a shallow phreatic level (in the study area). The arenosols (FAO/UNESCO 1998) of this area are derived from Pliocenic sandstones sometimes cemented by ferric oxides in the upper layers. In spite of the very high density of the sandstone layers (bulk density $1.8-1.9 \mathrm{Mg} / \mathrm{m}^{3}$ ), the perennial system of Quercus suber roots can penetrate in the deeper layers $(>3 \mathrm{~m})$ though discontinuity zones present in the geological material. The shallow loamy sand soils of the study area contain $15-20 \%$ of coarse material and have very high bulk density below $0.15 \mathrm{~m}$ depth, very low infiltration rates and saturated hydraulic conductivity $(<5 \mathrm{~mm} / \mathrm{h})$, moderate available water $(0.08 \mathrm{~m} / \mathrm{m})$, low $\mathrm{pH}(<5.5)$ and very low organic carbon ( $2 \mathrm{~g} \mathrm{C} / \mathrm{kg}$ soil) below $0.10 \mathrm{~m}$ depth.

Volumetric soil water content was measured from late February to early September by neutron moisture meter technique (model Troxler 4300, Troxler Electronic Laboratories, INC, Research Triangle Park, $\mathrm{NC}, \mathrm{USA}$ ) in 12 tubes down to $1.20 \mathrm{~m}$ in the soil. Measurements to $1.2 \mathrm{~m}$ depth were taken on DOY 79 , 92, 127, 141, 157, 174, 179, 189, 197, 213, 226 and 247 (20 March, 2 April, 7 May, 21 May, 6 June, 23 June, 28 June, 8 July, 16 July, 1 August, 14 August, 4 September, respectively). The tubes were located $20 \mathrm{~m}$ away from the tree under study, in row and interrow positions at $2.0 \mathrm{~m}$ and $5.0 \mathrm{~m}$ distance from the tree stem of four different plants.

Precipitation, solar radiation, air temperature and humidity, wind speed and direction and the components of the energy balance were recorded at the top of the canopy. Reference ET (ETo) was calculated using data from a nearby (Moinholas) standard meteorological station.

A single Quercus suber tree $(\mathrm{DBH}=0.52 \mathrm{~m}$, without cork) was selected for detailed measurements of water uptake (roots and stem). The position of the sensors on the sample tree is described in the Experimental design section.

Sap flow measurements

Sap flow in roots and stem was measured using the heat field deformation method, HFD, (Nadezhdina et al. 1998; Nadezhdina and Cermak 2000c; Cermak et al. 2004). The current sensor configuration for the HFD method is presented in Fig. 2b. It includes the heater radially installed in the sapwood and two pairs a

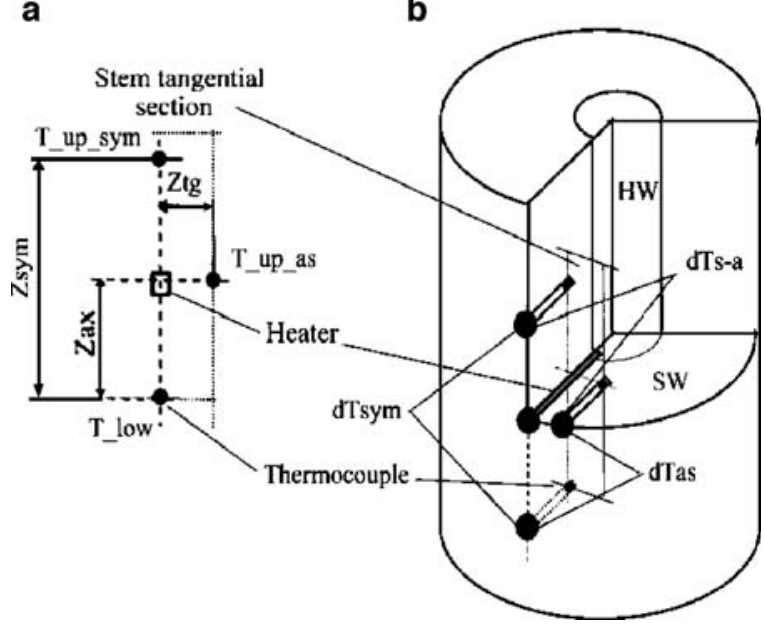

Fig. 2 a Scheme of the tangential section of stem xylem with arrangements of the thermocouples around the heater of the HFD sensor. b Scheme of the HFD-sensor installed in sapwood, SW, of a stem. Two differential pairs of thermocouples with a common lower end allow measurment of two temperature gradients: $\mathrm{d} T_{\text {sym }}$, and $\mathrm{d} T_{\text {as }}$. The third temperature gradient $\mathrm{d} T_{s-\mathrm{a}}$ can be calculated as a difference between measured $\mathrm{d} T_{\text {sym }}$ and $\mathrm{d} T_{\text {as. }}$. HW and SW denote heartwood and sapwood respectively

of differential copper-constantan thermocouples. The reference thermocouples of each pair of the differential thermocouples, measuring the temperature $T_{\text {low }}$ (see Fig. 2a), are inserted in one common needle placed below the heater. In the symmetrical pair of needles, the thermocouples are located equidistant, $Z_{\mathrm{ax}}$, from the heater in the axial direction $\left(Z_{\mathrm{ax}}\right.$ is equal to half of $\left.Z_{\text {sym }}\right)$. They measure the symmetrical temperature differences, $\mathrm{d} T_{\text {sym }}$, allowing bi-directional (acropetal and basipetal) measurements of very low flow rates (Nadezhdina 1988; 1998; 1999). In the asymmetrical pair of differential thermocouples, the upper sensor, measuring the temperature $T_{\text {_up_as, }}$, is placed at the distance $Z_{\mathrm{tg}}$ from the heater in the tangential direction. This pair of thermocouples, measuring the asymmetrical temperature difference, $\mathrm{d} T_{\text {as }}$, is mostly responsible for the magnitude of the medium and high sap flow rates.

Deformation of the heat field around a linear heater in a certain tangential section of the stem was taken as a measure of sap flow. In the HFD-method, sap flow density, $q$, was calculated as

$$
q=3600 D\left(K+\mathrm{d} T_{s-a}\right) \mathrm{d} T_{a s}^{-1} Z_{a x} A^{-1}, \quad\left[\mathrm{~cm}^{3} \mathrm{~cm}^{-2} \mathrm{~h}^{-1}\right],
$$


where $D$ is thermal diffusivity of green (fresh) wood. A nominal value for $D$ of $2.5 \times 10^{-3} \mathrm{~cm}^{2} \mathrm{~s}^{-1}$ was used, which was suggested by Marshall (1958). $\mathrm{d} T_{\mathrm{s}-\mathrm{a}}$ is the temperature difference between upper of the symmetrically and upper of the asymmetrically placed thermocouples which can be calculated from both measured temperature gradients:

$\mathrm{d} T_{\text {s-a }}=T_{\text {_up_sym }}-T_{\text {_up_as }}=\mathrm{d} T_{\text {sym }}-\mathrm{d} T_{\text {as }}$

The calculated temperature difference $\left(K+\mathrm{d} T_{\mathrm{s}-\mathrm{a}}\right)$ was found to be more suitable for sap flow calculation than simply $\mathrm{d} T_{\text {sym }}$ due to its better stability under high flow rates. Under low flow rates both $\mathrm{d} T_{\text {sym }}$ and $(K+$ $\left.\mathrm{d} T_{\mathrm{s}-\mathrm{a}}\right)$ are identical. $K=\left(\mathrm{d} T_{\mathrm{s}-\mathrm{a}}\right)_{0}$ is the absolute value of temperature differences $\mathrm{d} T_{\mathrm{s}-\mathrm{a}}$ or $\mathrm{d} T_{\text {as }}\left({ }^{\circ} \mathrm{C}\right)$ under conditions of zero-flow when the absolute values of both temperature differences are equal but of opposite sign. Parameter $K$ includes all basic information about the measurement location including: wood properties, power supply and sensor geometry. $A$ is the measured conducting area $\left[\mathrm{cm}^{2}\right]$ where deformation of the heat field is studied. This area is limited by the heater and the upper end of asymmetrical thermocouples and depth of sapwood, $L_{\mathrm{sw}}$ :

$A=L_{s w} Z_{t g}$

where $L_{\mathrm{sw}}(\mathrm{cm})$ could be determined from measurements of the sap flow radial pattern by the radial profile sensor or distinguished from heartwood based on xylem water content or wood color. Because $L_{\mathrm{sw}}$ is often not known before measurement, sap flow could be calculated as so-called sap flow per section, $q_{\mathrm{s}}$ :

$$
q s=3600 D\left(K+\mathrm{d} T_{\mathrm{s}-\mathrm{a}}\right) \mathrm{d} T_{\mathrm{as}}^{-1} Z_{\mathrm{ax}} Z_{\mathrm{tg}}^{-1}\left[\mathrm{~cm}^{3} \mathrm{~cm}^{-1} \mathrm{~h}^{-1}\right]
$$

and $q_{\mathrm{s}}$ could later be converted to $q$ by dividing by $L_{\text {sw }}$ after identification of the sapwood depth.

Only qualitative variability and direction of sap flow in roots and stem of cork oak were studied during the growing season, therefore, primary data of sap flow per section (surrogate of sap flow density) was used for the analysis without further conversion into sap flow density as was done by Oliveira et al. (2005).
The same sensor configuration was used to record the reverse flow, but flow direction (and thus, changing temperature gradients) were taken into consideration. When diurnal values of $\mathrm{d} T_{\text {sym }}$ become negative, the Eq. 4 was transformed to:

$$
\begin{gathered}
q s=-3600 D \times\left(\left(-K+\mathrm{d} T_{\mathrm{as}}\right) / \mathrm{d} T_{\mathrm{s}-\mathrm{a}}\right) \times\left(Z_{\mathrm{ax}} / Z_{\mathrm{tg}}\right)(5) \\
{\left[\mathrm{cm}^{3} \mathrm{~cm}^{-1} \mathrm{~h}^{-1}\right]}
\end{gathered}
$$

Two sensor modifications were used for sap flow investigations: the multi-point sensors (long) for the determination of the pattern of flow along the xylem radius in tree stems and the single-point sensors (short) for measurements of flow in small roots. Each sap flow sensor consists of a linear heater and two sets of differential thermocouples measuring temperature differences around the heater. Both the heater and the differential thermocouples were placed into stainless steel hypodermic needles with an outer diameter of $1.2 \mathrm{~mm}$ and $1.5 \mathrm{~mm}$ for single and multi-point sensors, respectively. The single-point sensor contained one thermocouple, at $5 \mathrm{~mm}$ from its head. The multi-point sensor contained five thermocouples, $6 \mathrm{~mm}$ apart (except one with $10 \mathrm{~mm}$ ). The distance of the first thermocouple was $20 \mathrm{~mm}$ from the head of the needle; thus the measuring length of the multi-point sensors was $44 \mathrm{~mm}$ (or $60 \mathrm{~mm}$ ). The heating power is low (range of 0.06-0.09 W per unit length (cm) of the heater). Data were recorded with 10 min intervals by Unilog dataloggers Midi-12 (Brno, Czech Republic) for single sensors in roots and by Delta_T 2LDe loggers with multiplexers (Cambridge, Great Britain) for multi-point sensors in the stem.

\section{Experimental design}

Five lateral roots of similar size were selected by carefully exploring the root system starting from the stem and then equipped with the single-point HFD sensors. The depth of the measured roots in the soil varied from 0.15 to $0.35 \mathrm{~m}$ at the place of the sensor installation. The sensors were installed on the top surface of these roots at the distance of 1.15 to $2.15 \mathrm{~m}$ from the tree trunk in different azimuthal directions (Table 1 - roots were renamed according to their behaviour as explained in section "Results"). Then sensors were shielded by silicon rubber and covered by soil again. After the end of the measurements, 
Table 1 Main characteristics of the single-point sensor installation on small lateral roots of a Quercus suber tree

\begin{tabular}{lllll}
\hline $\begin{array}{l}\text { Designation of } \\
\text { the measured } \\
\text { root }\end{array}$ & $\begin{array}{l}\text { Root } \\
\text { diameter } \\
(\mathrm{mm})\end{array}$ & Azimuth & $\begin{array}{l}\text { Soil } \\
\text { depth } \\
(\mathrm{cm})\end{array}$ & $\begin{array}{l}\text { Distance from } \\
\text { tree trunk } \\
(\mathrm{cm})\end{array}$ \\
\hline N1 & 33 & $\mathrm{~S}$ & 20 & 115 \\
N2 & 38 & E & 35 & 215 \\
P1 & 30 & W & 35 & 180 \\
P2 & 38 & NE & 23 & 155 \\
P3 & 35 & E & 20 & 212
\end{tabular}

The labels $N$ and $P$ mark roots with "Negative" or "Positive" night flow recorded during drought.

roots were excavated extensively in order to observe their links with sinkers and corresponding rooting depths. Root N1 was confirmed to be shallow, because it was a very superficial lateral root without sinkers attached. However, this root was branched from other large lateral roots having sinkers and thus root N1 had a chance to use lifted water through this connection (Nadezhdina et al. 2006). Root P1 had a deep sinker attached to it at the distance $2.6 \mathrm{~m}$ from stem base and downstream in relation to the point of sensor installation. Root P1 gradually became deeper by itself too. That is why this lateral root with distant sinker attached to it was classified as a deep root with function similar to deep roots emanating directly beneath the stem.

Four multi-point HFD sensors were installed at the trunk base of the tree at four cardinal points. The five pairs of differential thermocouples of each sensor characterized the sap flow radial pattern from the measured stem sides. For simplicity, during further analysis (comparison of fluxes in individual roots with trunk xylem at different radial depths) we used only two measured depths below the cambium - the outer and the inner. The first thermocouples were at the sapwood depth 4-6 $\mathrm{mm}$ from the cambium and this trunk xylem depth was classified as the outer xylem. Sapwood depth around $25 \mathrm{~mm}$ below the cambium was taken as the inner stem xylem.

All sensors were installed in the beginning of March, when ground water was very close to surface (around $30 \mathrm{~cm}$ ). Measurements in roots were finished by the middle of September, while trunk measurements lasted until the end of November.

\section{Results}

Sap flow in roots

Some of the five lateral roots had quite similar sap flow patterns, for example, roots P1, P2 and P3 (Fig. 3). Roots could be divided in two main groups according to their sap flow behaviour (Figs. 3, 4): roots which did not show a significant decrease of sap flow during dry periods and always showed a positive flow (roots P1, P2 and P3) and roots in which daytime flows decreased with increasing drought and flows reversed toward the soil during the night (roots N1 and N2; Fig. 4a,d). Strong linear relationships were found between roots with positive flow during the growing season, both for night and day periods (Fig. 4b,e). However, there was no relationship, on a seasonal basis, between roots from different groups (P1 versus N1 and N2, Fig. 4c,f).

Long term patterns of sap flow were different in representative roots from each group $\mathrm{N} 1$ and $\mathrm{P} 1$ (Fig. 5). Flow in root N1 was highest in March (DOY 60 to 90), but lowest in summer until August 26 (DOY 238) when positive flow during day occurred only for 5 h 30 min. Rains in late August (Fig. 5d) modified the daily pattern of sap flow in all roots, practically resuming the wet spring pattern. Root N1 had the highest and longest nighttime reverse flow that started to occur from the middle of June (DOY 152). Later, from DOY 216 on, the nighttime reverse flow was also recorded in root N2 (Fig. 3j,k and Fig. 4a). During nights, when reverse flow occurred in roots $\mathrm{N} 1$ and $\mathrm{N} 2$, the other roots had rather high flows, evidently having access to groundwater (Fig. 3c,d,e).

Beginning the middle of June (DOY 166), soil water availability rapidly decreased due to the high evaporative demand and lack of rain (Fig. 5b,c,d) and sap flow in roots N1 and P1 was always in anti-phase, i.e. a decrease of daily and night flow in N1 was accompanied by an increase of flow in P1 (Fig. 5a). Reverse flow started in root N1 when available water in upper soil layers $(0-30 \mathrm{~cm})$ decreased to $10 \%$, corresponding to less then $5 \%$ of volumetric soil water content. Water depletion in the topsoil was very rapid after spring rains stopped, but the rate of water depletion declined later when HR started to occur.

The first late summer rain $(2 \mathrm{~mm})$ occurred on August 27, followed by $8 \mathrm{~mm}$ the next day and heavy 
Fig. 3 Examples of diurnal sap flow dynamics in five lateral roots of a Quercus suber tree for chosen typical days of the investigated period. The weather conditions were very similar for each of these days with sunny cloudless sky and maximum air temperature between $23-32^{\circ} \mathrm{C}$. Potential evapotranspiration for the shown days was $2.6 ; 4.7 ; 6.4 ; 5.4 ; 4$ and $3.4 \mathrm{~mm}$ day $^{-1}$, respectively. Soil water content declined gradually from March to August and then season rains occurred in late August/ early September (see also changes of soil moisture conditions in Fig. 5b). Roots P1, P2 and P3 with continuous positive flow are shown in left panels (a-f) and roots N1 and N2 with reverse night flow observed during drought are shown in right panels (g-l)

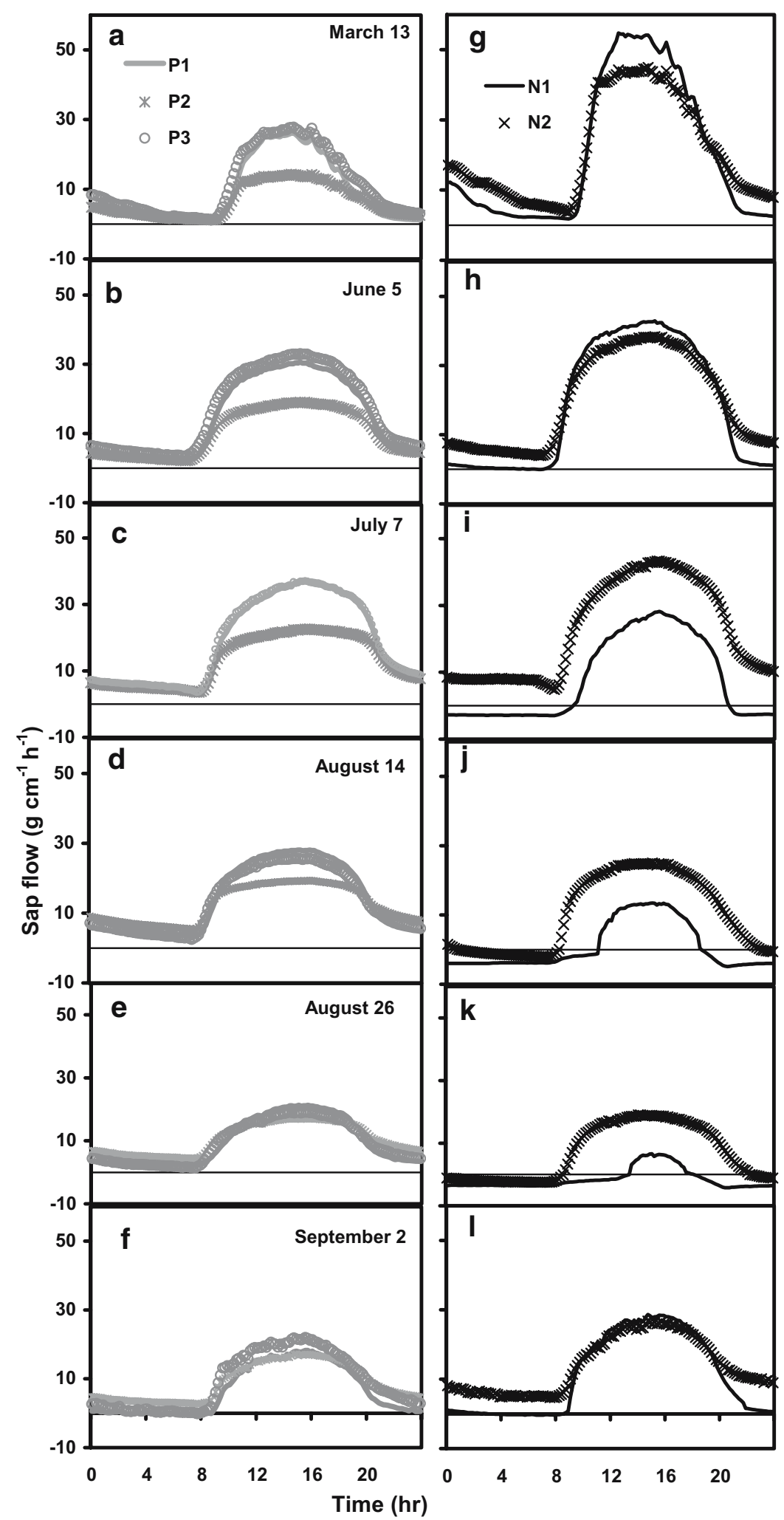



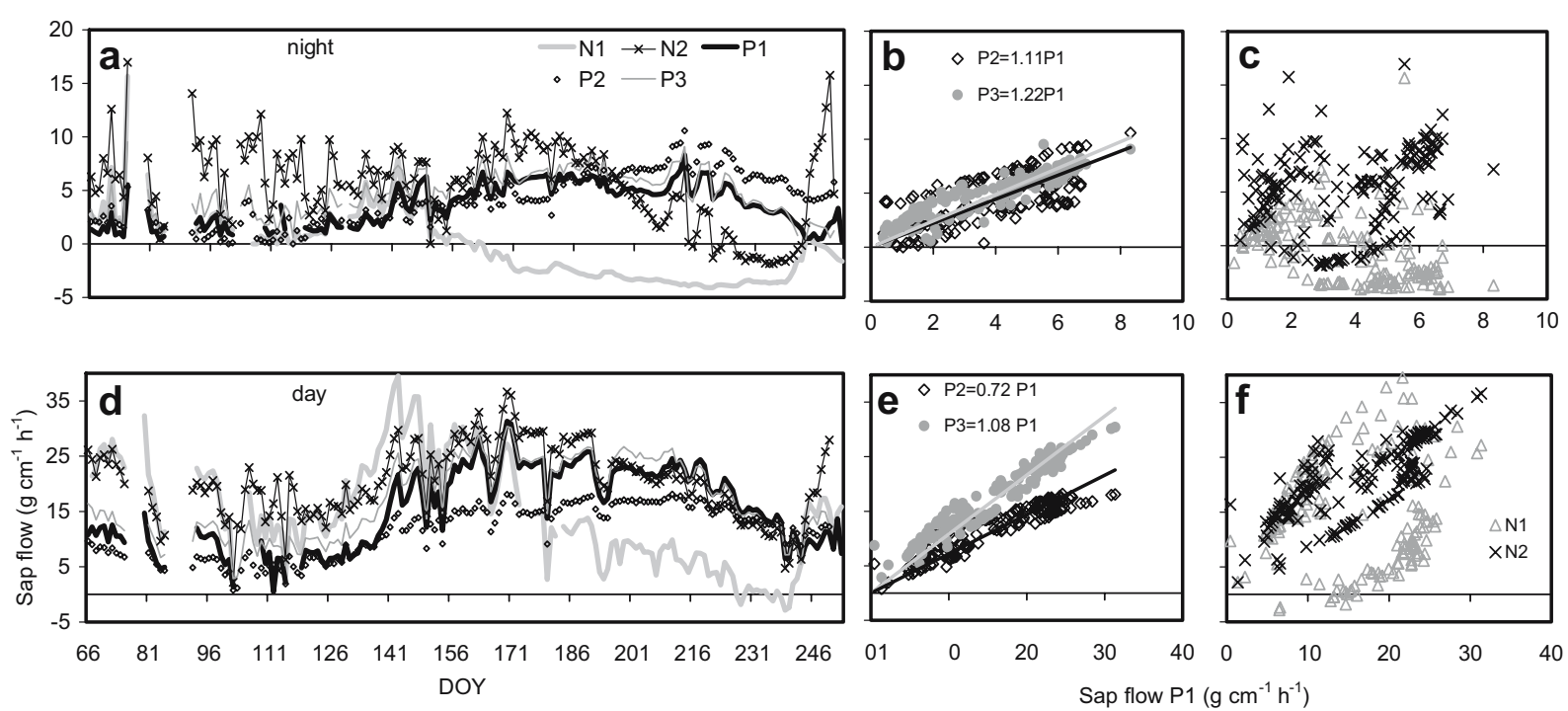

Fig. 4 Nighttime (a) and daytime (d) sap flow in five lateral roots of a Quercus suber tree, during the year 2003 (from March to September). Sap flow values are mean rates calculated from measurements taken every 10 min between 6 and $22 \mathrm{~h}$ (day) and 22 and $6 \mathrm{~h}$ (night). Relationships between sap flow in root P1 and all other roots were calculated separately for night $(\mathbf{b}, \mathbf{c})$ and day $(\mathbf{e}, \mathbf{f})$ periods. A highly

rain $(24.6 \mathrm{~mm})$ on August 31 (Figs. 6 and 5d). As shown in Fig. 6a, no positive flow was recorded in root N1 during the first two rainy days (August 27 and 28), when leaf water potential was evidently higher than soil water potential in upper layers, due to low evaporative demands and low rain intensity. The duration and magnitude of reverse night flow decreased while the duration of daily positive flow substantially increased in root N1 after those two rainy days (Fig. 6a). After the heavy rain in August 31 , no more reverse flow was observed in root N1. Daily flow in root N1 increased substantially while flow in root P1 decreased compared with the period of summer drought. Daily sap flow dynamics became comparable in both roots after these late summer rain events.

Sap flow at trunk base

The features described above on different root functioning were also reflected in sap flow recorded at different xylem depths at the trunk base. Figure 7 shows correlation coefficients (Fig. 7a) and the slopes (Fig. 7b) of the relationships between sap flow in shallow N1 and deep P1 roots, as well as, between

correlated linear relationship was found between sap flow in root $\mathrm{P} 1$ and roots $\mathrm{P} 2$ and $\mathrm{P} 3$ with continuous positive flow. Equations of relationships are shown in legends to panels $(\mathbf{b}, \mathbf{e})$. Correlation coefficients $\left(R^{2}\right)$ were higher for days $(0.79$ and $0.90)$ than for nights $(0.46$ and 0.74$)$ for roots P2 and P3 respectively. There were no correlations between root $\mathrm{P} 1$ and roots N1 and N2 with reverse flow recorded during drought

sap flow in the outer and the inner trunk xylem. The higher sap flow in root N1 compared to root P1 in March-May sharply decreased with drought development in June-August (Fig. 7b). Sap flow in root N1 abruptly increased again after the rains in late August. The same tendency was observed in the outer trunk xylem from all sides of the tree when compared with the inner trunk xylem (only two sides are shown for simplicity in Fig. 7). However, the decrease in the slope of the linear regression between trunk xylem was not so abrupt as for the relationship in roots. The correlation of regression for roots also sharply decreased with soil drying (Fig. 7a). However, it was always very strong for trunk xylem. Changes of functional links between shallow and deep roots and different stem xylem during the growing season are shown in Fig. 8. When soil was wet (data for MarchMay shown in the dotted circle in Fig. 8a) flow in shallow root was double that in the deep root and flow in the outer and inner xylem was similar. As drought developed, flow in the deep root substantially increased compared with the shallow root. These changes to the deep root increased flow in both the outer and inner xylem, however, the increase was more substantial for the inner xylem to which 
Fig. 5 Seasonal sap flow dynamics in two lateral roots $\mathrm{N} 1$ and $\mathrm{P} 1$ of a Quercus suber tree (a), seasonal change of available water in two soil layers (b), potential evapotranspiration (c) and precipitation (d) during the growing season 2003
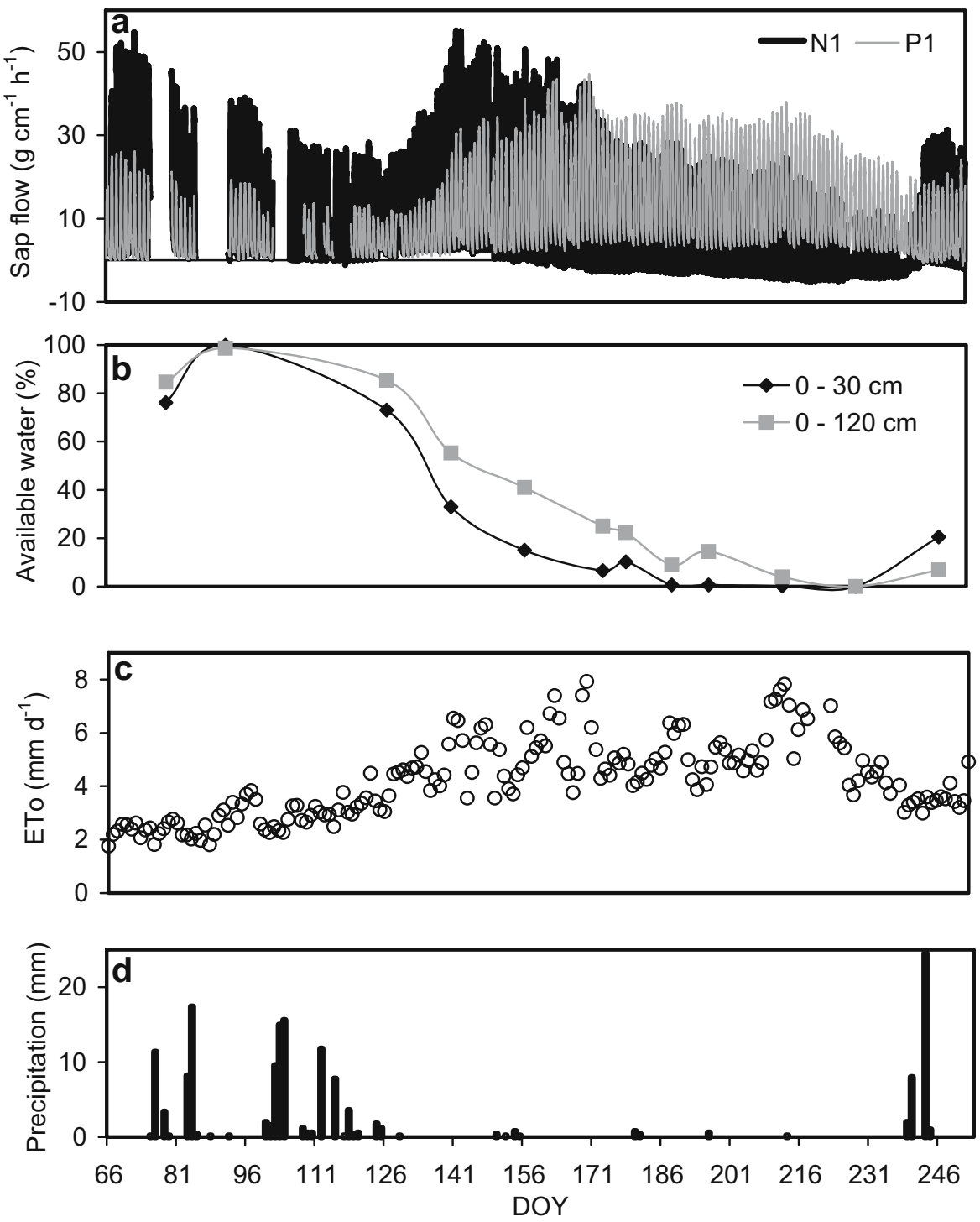

majority of deep roots should be directly connected (left side of Fig. 8a). These results also suggest direct connection between the outer xylem and shallow root (by stronger coefficient of correlation between root N1 and the outer stem xylem).

\section{Discussion}

Sap flow in roots and at the trunk base

Long-term positive sap flow dynamics in roots $\mathrm{P} 1$, P2 and P3 indicate that they had constant access to ground water. The importance of these roots for the total water uptake decreased after the late summer rains with the corresponding increase in availability of water in the upper soil layers, as indicated by no increase in sap flow in these roots after rains (Fig. 4d). The reverse flow recorded in roots N1 and $\mathrm{N} 2$ at night during the dry period of the growing season (see Figs. 3 and 4), indicates that water obtained from deeper sources was used for re-hydration of root tissue and presumably the local rhizosphere. The latter could be the reason for slowing the decrease in soil moisture content in the topsoil (Fig. 5b), although changes to evaporation rates from the drying soil are 
Fig. 6 Sap flow dynamics in two small lateral roots N1 and $\mathrm{P} 1$ at the end of the dry period - detail of Fig. 5 for the period DOY 236 to 246 , inclusive - (a), scheme of these roots with location of the sap flow sensors relative to sinker positions (b) and photos of excavated roots $\mathrm{N} 1$ - vertical photo (c) and P1 - horizontal photo (d). No sinkers were found in lateral superficial root N1 after sensor position (in the distant part of the root in direction from the stem), whereas several sinkers were connected to root P1 after the place of sensor installation

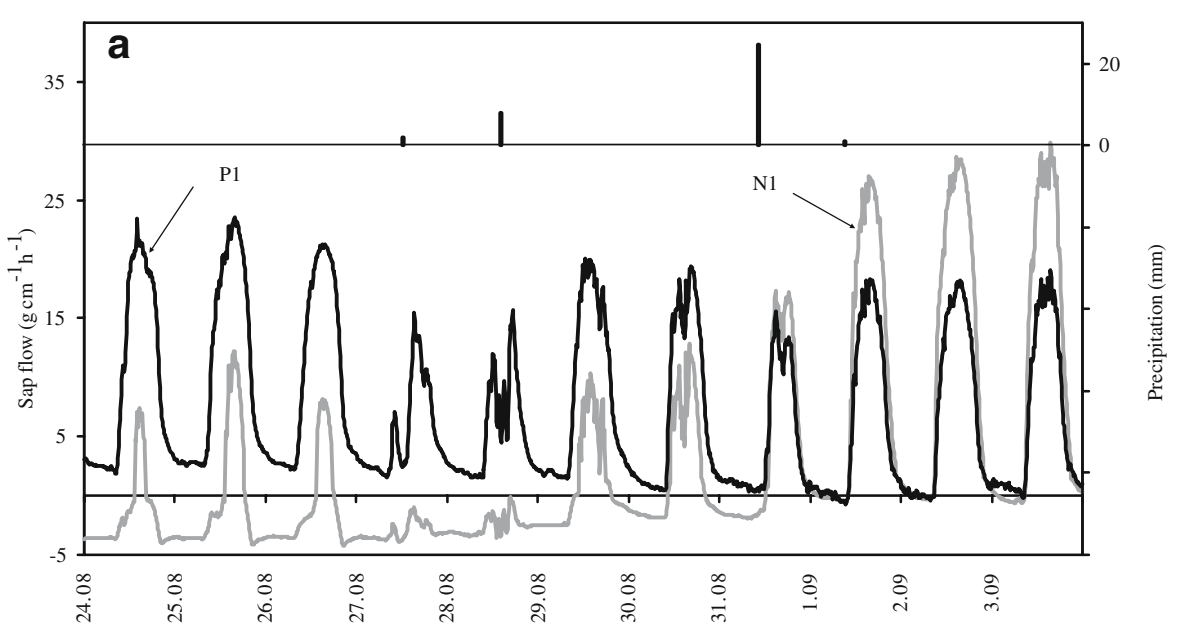

b

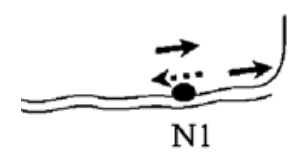

C

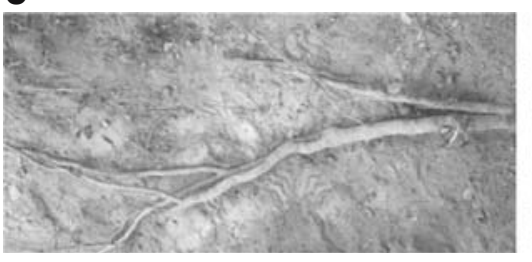

d

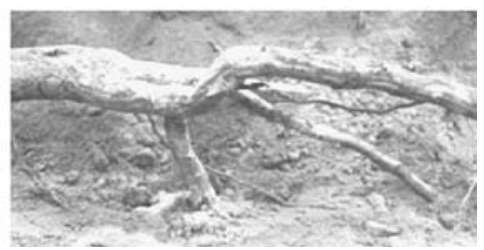

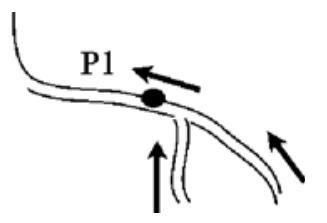

also a likely contributor. Brooks et al. (2006) indicated that pathways connecting wetter deep soil and surface dry soil for HR could be very localized contributing to the patchy nature of HR.

Several studies reporting sap flow measurements in roots and trunk (Burgess et al. 2000b; Fernandez et al. 2001; Scholz et al. 2002; Hultine et al. 2003, Burgess and Bleby 2006) demonstrate root behaviour in relation to water transport in trunk. It was shown that drought developed in topsoil can lead to a relative increase in the contribution of inner xylem to wholetree water uptake (Nadezhdina et al. 2002, Ford et al. 2004). However, direct links of stem xylem with root function was not studied in these works. Night sap flow was higher in the inner than in the outer xylem in the majority of the large roots of spruce trees under drought, which indicated a connection of the inner root conducting xylem with the sinker roots (Nadezhdina et al. 2006). Sap flow in several depths of the outer stem xylem of a solitary Black pine tree was measured with half of its root system exposed to air by excavation to the depth of around $1 \mathrm{~m}$ under tree base. No response of sap flow occurred in the outer stem xylem when sinker roots under stem base were cut; however, flow decreased immediately after surface root cutting (Nadezhdina and Čermák unpublished data),

To our knowledge, this is the first report of links between sap flow in roots and different trunk xylem depths, based on long-term sap flow monitoring under natural conditions. Below, we list five key observations from the long term data gathered in this study. (1) Good flow correlation between root N1 and root P1 only when soil was wet. There were little differences in soil water potential between different soil horizons and water uptake of both roots was similar. (2) Flows in the shallow root and the outer trunk xylem were related and the relationship between them went through the origin under wet soil conditions. Later, sap flow in both shallow root and the outer xylem was suppressed by drought. The slope of the 
Fig. 7 Monthly changes of statistical parameters of relationships (a correlation coefficients and $\mathbf{b}$ slopes of linear regressions forced through zero) between sap flow in shallow N1 and deep P1 roots (lines without symbols) and between sap flow in the outer and the inner trunk xylem recorded from the southern (lines with open triangles) and western (lines with full rectangles) sides
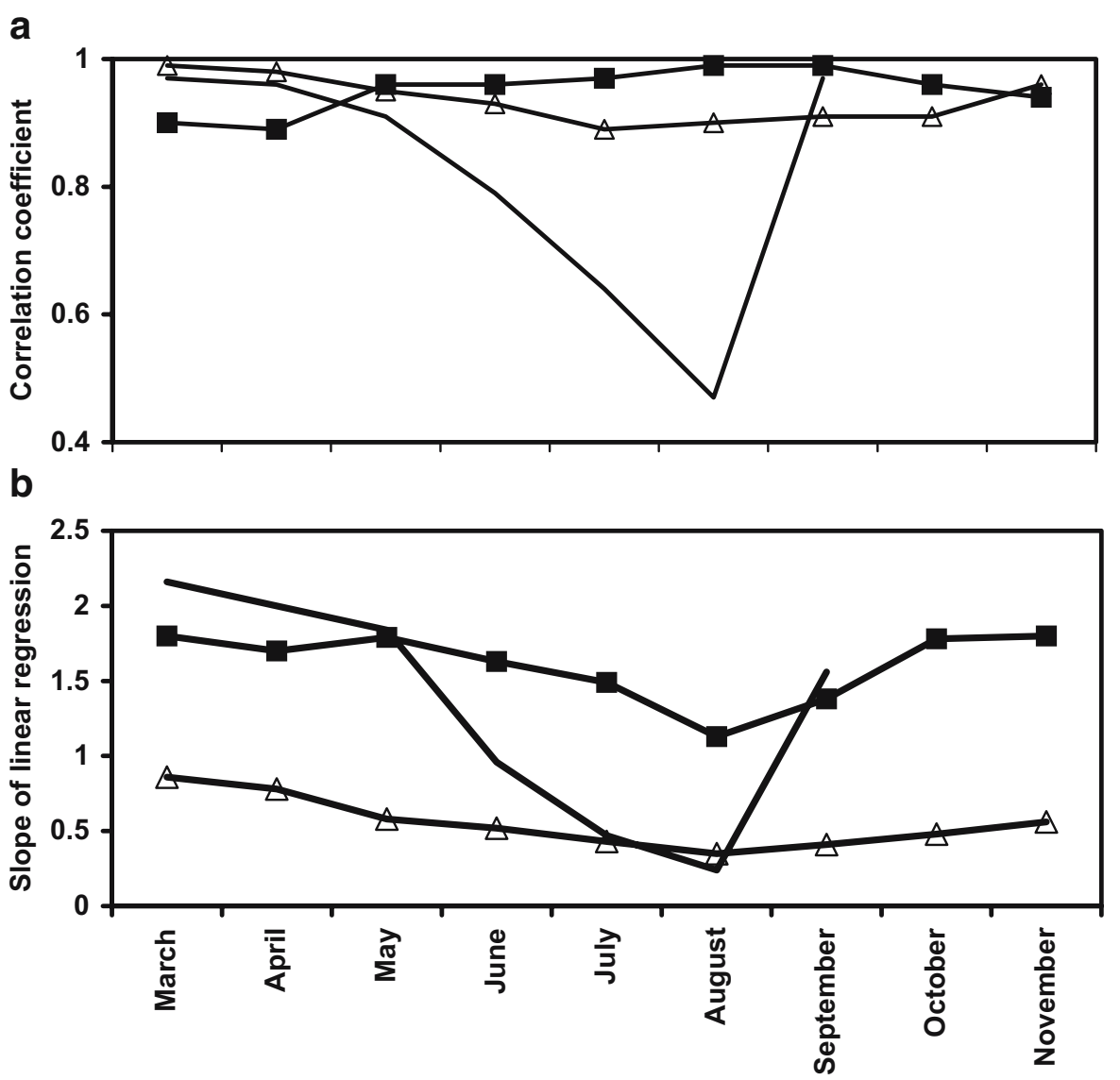

relationship between them did not change throughout the observed period even with soil drying (data not shown). However, positive flow in root N1 started to occur under already rather high flow in the outer trunk xylem. This suggests that other surface roots with sinkers are connected to the outer xylem where flow is integrated from several roots. Flow from sinkers attached to shallow roots may go in both directions, acropetal and basipetal, depending on competing sinks, number of sinkers and distance from the stem base. Decreases in daily flow in both shallow lateral roots and the outer stem xylem layers with soil drought suggests a correspondence of this stem xylem layer with the most superficial soil horizons. (3) Similarity of relationships between N1 versus P1 and N1 versus the inner xylem. Sap flow increased in deep root $\mathrm{P} 1$ and in the inner xylem with drought development. This could suggest that water flow in the inner sapwood was maintained high because of its direct connection to sinker roots, which would behave similarly to the sinker-bearing P1, under the trunk. Evidently, this part of the xylem had no competing sink (acting in opposite direction) as the outer xylem had. Our finding suggests that higher relative water uptake of deep roots can be evaluated through increased relative flow in the inner xylem. (4) The correlation between sap flow in deep root P1 and the whole stem xylem was very high and went through the origin during the entire growing season (data not shown), indicating permanent trunk water supply through deep/sinker roots (in the case of outer xylem - through sinkers connected to shallow roots). That is why a strong relationship was also found between sap flow in the outer versus inner trunk xylem though the entire studied period. This could also indicate possible interconnection between water pathways in trunk xylem. (5) The ratio of sap flow in the inner to the outer xylem increased with soil drying. This ratio substantially varied with azimuthal position, because of the integration of 

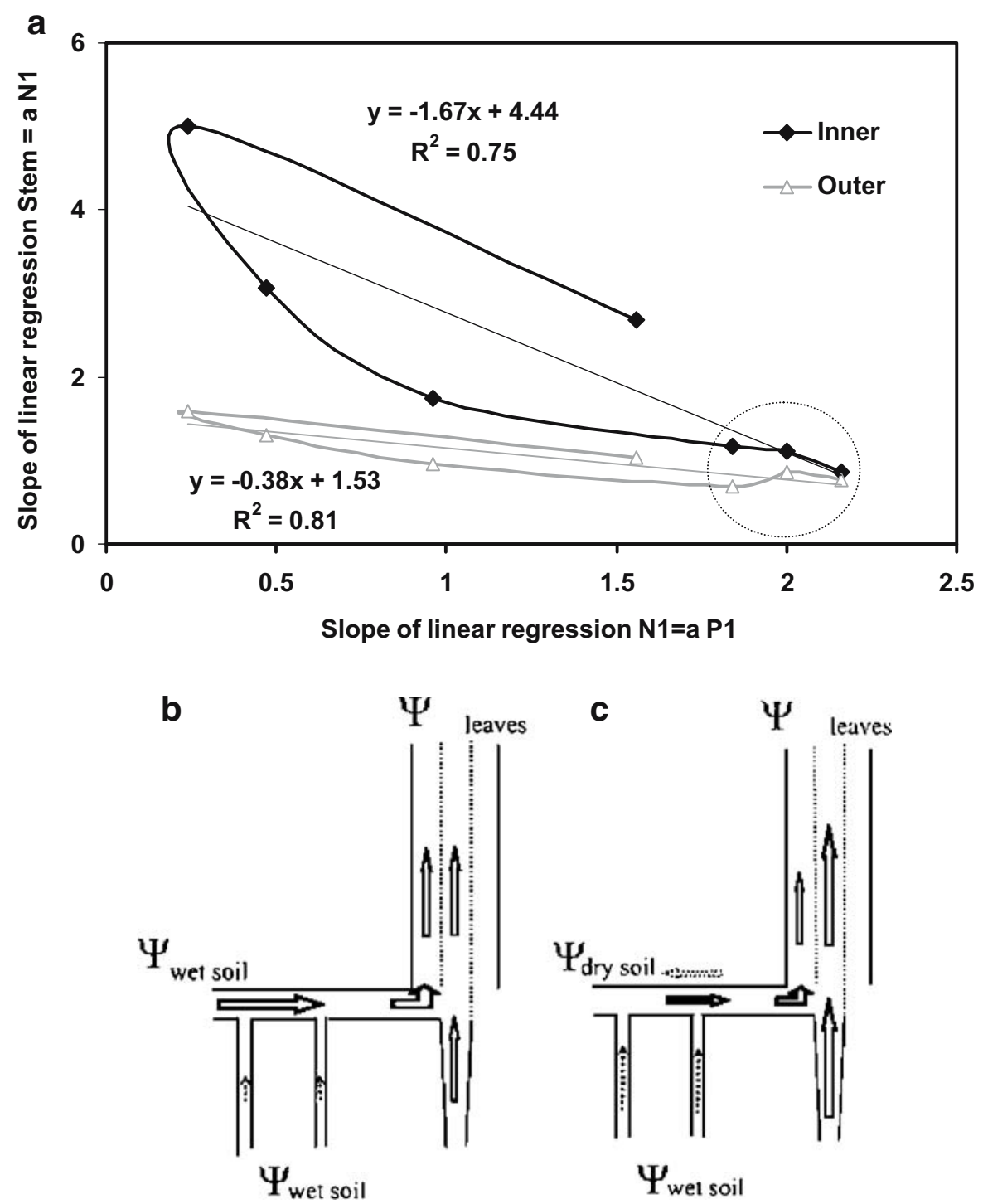

Fig. 8 Monthly changes of statistical parameters of relationships between sap flow in shallow $\mathrm{N} 1$ and deep P1 roots (XX' axis) and between sap flow in the outer (open triangles) and the inner trunk xylem (closed squares), for the southern side and shallow root N1 (YY' axis) (a). Conceptual schemes of water

uptake from different soil horizons and links of shallow and deep roots with the outer and the inner stem xylem for periods with wet (b) and dry (c) surface soil. Night reverse flow in a shallow root during drought is shown by dotted arrow

water pathways from roots is the lowest at trunk base (Cermak and Kucera 1990).

Our long-term observations of functioning roots and stem xylem of a Quercus suber tree are summarized in the hypothetical schemes separately for wet and dry periods of the growing season (Fig. $8 \mathrm{~b}$ and c, respectively). Recognizing that only single tree was under study with limiting number of roots we have to admit that the interpretation of these observations suggest the occurrence of processes of interest, which remain to be quantified for their importance at the stand level.

Sap flow sensor placement in roots and the understanding of root architecture

The analysis of the results reported in the literature concerning HR suggests that experimental design is 
extremely important. The majority of the authors installed sap flow sensors on roots near the tree trunk (Burgess et al. 1998, 2000b; Scholz et al. 2002; Moreira et al. 2003; Hultine et al. 2003). Only Brooks et al. (2002) placed sensors in large lateral roots as much as $1-2 \mathrm{~m}$ from the tree trunk, but they studied horizontal water redistribution through roots. The authors investigating HR between vertical soil horizons did not find evidence of water lifting in all roots measured close to the proximal collars.

Results also demonstrate the importance of the sap flow sensor placement, in relation to sinker roots, as to whether lateral roots might be found to exhibit reverse flow during drought (see Fig. 6b). There were no sinkers on root N1 (Fig. 6b,c) and the sensor recorded high flow in this root only when the surface soil was wet. Conversely, when the soil surface was dry, root N1 can be supplied by water through other surface roots with sinkers attached. By exposing the whole root system around stem after the experiment, we saw a very complicated network of surface roots with many interconnections among them. The sensor on root P1 was installed between the trunk and the sinkers (Fig. 6b, d). In such case, the sensor always recorded water movement for transpiration from deeper soil horizons.

Several past studies have given an indication of the influence of sensor placement in lateral roots on sap flow. Hultine et al. (2003) detected nocturnal reverse flow in shallow lateral roots of Fraxinus velutina and Juglans major trees during periods of dry surface soil. No reverse flow was found in roots of Celtis reticulata. At the same time, sensors at all trees were installed only a few $\mathrm{cm}$ from the proximal root collars. The authors noted, that Fraxinus velutina and Juglans major displayed typical dimorphic root distributions, with a network of shallow (1 m deep) lateral roots and deep taproots, whereas Celtis reticulata did not have a discernable taproot and all the lateral roots contained sinker roots that extended below $1 \mathrm{~m}$, and secondary lateral roots that remained above $1 \mathrm{~m}$. Thus, absence of reverse flow in Celtis reticulate roots could be explained by the position of sensors, similar to the ones in our study, shown in Fig. 6b,d.

The probability of having sinkers between the place of measurement on the root and the trunk would be lower when sensors are placed closer to the proximal root collars. Thus, the type of root system and placement of sap flow sensors on roots should be taken into account during studies of HR. Opposite night sap flow direction was detected by many authors (Burgess et al. 2001b; Oliveira et al. 2005) in lateral and tap roots during both, dry and wet periods. Night sap flow in laterals containing sinkers may be in the opposite direction only during drought as was shown in the results of our study.

Our long-term study of water uptake by Quercus suber demonstrated that: (1) HR exists in cork oak; (2) dimorphic root system is complicated by secondary sinkers; (3) probe placement is important with reference to secondary sinkers; (4) outer xylem is more closely coupled to superficial rooting systém and (5) quantification of HR in oak silvopastoral systems via more replication and with attention to the above insights is our next study.

Acknowledgements The research was supported by the project WATERUSE: EVK1-2000-00079EU. The authors are grateful to Nadezhdin Valeriy, Filipa Neto and Ana Costa Dias for technical support in the field and to Hamlyn Jones and Tom Trout for their valuable suggestions and English corrections. The constructive and helpful comments from two anonymous reviewers and Stephen Burgess were greatly appreciated.

\section{References}

Brooks JR, Meinzer FC, Coulombe R, Gregg J (2002) Hydraulic redistribution of soil water during summer drought in two contrasting Pacific northwest coniferous forests. Tree Phisiol 22:1107-1117

Brooks JR, Meinzer FC, Warren JM, Domec JC, Coulombe R (2006) Hydraulic redistribution in a Douglas-fir forest: lessons from system manipulations. Plant Cell Environ 29(1):138-150

Burgess SSO, Adams MA, Turner NC, Ong CK (1998) The redistribution of soil water by tree root systems. Oecologia 115:306-311

Burgess SSO, Adams MA, Bleby TM (2000a) Measurement of sap flow in roots of woody plants: a commentary. Tree Physiol 20:909-913

Burgess SSO, Pate JS, Adams MA, Dawson TE (2000b) Seasonal water acquisition and redistribution in the Australian woody phreatophyte Banksia prionotes. Ann Bot 85:215-224

Burgess SSO, Adams MA, Turner NC, Beverly CR, Ong CK, Khan AAH, Bleby TM (2001a) An improved heat pulse method to measure low and reverse rates of sap flow in woody plants. Tree Physiol 21:589-598

Burgess SSO, Adams MA, Turner NC, White DA, Ong CK (2001b) Tree roots: conduits for deep recharge of soil water. Oecologia 126:158-165 
Burgess SSO, Bleby TM (2006) Redistribution of soil water by lateral roots mediated by stem tissues. J Exp Bot 57:32833291

Cabibel B, Do F (1991) Thermal measurement of sap flow and hydric behavior of trees. 2. Sap flow evolution and hydric behavior of irrigated and non-irrigated trees under trickle irrigation. Agronomie 11:757-766

Caldwell MM, Richards JH (1989) Hydraulic lift: water efflux from upper roots improves effectiveness of water uptake by deep roots. Oecologia 79:1-5

Caldwell MM, Dawson TE, Richards JH (1998) Hydraulic lift consequences of water efflux from the roots of plants. Oecologia 113:151-161

Cermak J, Kucera J (1990) Scaling up transpiration data between trees, stands and watersheds. Silva Carelica 15:101-120

Cermak J, Kucera J, Nadezhdina N (2004) Sap flow measurements with some thermodynamic methods, flow integration within trees and scaling up from sample trees to entire forest stands. Trees 18:529-546

Clothier BE, Green SR (1997) Roots: the big movers or water and chemical in soil. Soil Sci 162:534-543

Dawson TE (1993) Hydraulic lift and water use by plants: implications for water balance, performance and plantplant interactions. Oecologia 95:565-574

Dawson TE, Pate JS (1996) Seasonal water uptake and movement in root systems of Australian phraeatophyc plants of dimorphic root morphology: a stable isotope investigation. Oecologia 107:13-20

Domec JC, Warren JM, Meinzer FC, Brooks JR, Coulombe R (2004) Native root xylem embolism and stomatal closure in stands of Douglas-fir and ponderosa pine: mitigation by hydraulic redistribution. Oecologia 141:7-16

Emerman S (1996) Towards a theory of hydraulic lift in trees and shrubs. In HJ Morel-Seytoux (ed) Sixteenth American Geophysical Union hydrology days. Hydrology Days. Atherton, California, pp 147-157

Fernandez JE, Palomo MJ, Diaz-Espejo A, Clothier BE, Green SR, Giron IF, Moreno F (2001) Heat-pulse measurements of sap flow in olives for automating irrigation: tests, root flow and diagnostics of water stress. Agr Water Manage 51:99-123

Ford CR, McGuire MA, Mitchell RJ, Teskey RO (2004) Assessing variation in the radial profile of sap flux density in Pinus species and its effect on daily water use. Tree Physiol 24:241-249

Granier A (1985) Une nouvelle methode pour la mesure dy flux de seve brute dans le trons des arbres. Ann Sci For 22:193-200

Green SR, Clothier BE, MclLeod DJ (1997) The response of sap flow in apple roots to localised irrigation. Agric Water Manage 33:63-78

Green SR, Vogeler I, Clothier BE, Mills TM, van den Dijssel C (2003) Modelling water uptake by a mature apple tree. Austr J Soil Research 41:365-380

Horton JL, Hart SC (1998) Hydraulic lift - a potentially important ecosystem process. Trends Ecol Evol 13:232-235

Huber B (1932) Beobachtung und Messung pflanzlicher Saftstrome. Berliner Deutsche Botanisches Geselschaft 50:89-109

Hultine KR, Williams DG, Burgess SSO, Keefer TO (2003) Contrasting patterns of hydraulic redistribution in three desert phreatophytes. Oecologia 135:167-175
Jackson RB, Moore LA, Hoffmann WH, Pockman WT, Linder CR (1999) Ecosystem rooting depth determined with caves and DNA. Proc Natl Acad Sci USA 96:11387-11392

Jackson RB, Sperry JS, Dawson TE (2000) Root water uptake and transport: using physiological processes in global predictions. Trends Plant Sci 5:484-491

Kurz-Besson C, Otieno D, Lobo do Vale R, Siegwolf R, Schmidt M, Herd A, Nogueira C, Soares David T, Soares David J, Tenhunen J, Santos Pereira J, Chaves M (2006) Hydraulic lift in cork oak trees in a savannah type Mediterranean ecosystem and its contribution to the local water balance. Plant Soil 282:361-378

Lott JE, Khan AAH, Ong CK, Black CR (1996) Sap flow measurements of lateral tree roots in agroforestry systems. Tree Physiol 16:995-1001

MADRP (2000) O sobreiro e a cortiça, um património, uma herança a preservar / The cork oak and cork, universal heritage, a legacy to be protected. Ministério da Agricultura, do Desenvolvimento Rural e das Pescas, Lisboa

Marshall DC (1958) Measurements of sap flow in conifers by heat transport. Plant Physiol 33:385-396

Meinzer FC, Brooks JR, Bucci SJ, Goldstein GH, Scholz FG, Warren JM (2004) Converging patterns of uptake and hydraulic redistribution of soil water in contrasting woody vegetation types. Tree Physiol 24:919-928

Moreno F, Fernández JE, Clothier BE, Green SR (1996) Transpiration and root water uptake by olive trees. Plant Soil 184:85-96

Moreira MZ, Scholz FG, Bucci SJ, Sternberg LS, Goldstein G, Meinzer FC, Franco AC (2003) Hydraulic lift in a neotropical savanna. Funct Ecol 17:573-581

Nadezhdina N, Cermak J (2000a) Responses of sap flow in spruce roots to mechanical injury. In Klimo E, Hager H, Kulhavy J (eds) Spruce monocultures in central Europe: problems and prospects. EFI Proc No 33, pp 167-175

Nadezhdina N, Cermak J (2000b) Responses of sap flow rate along tree stem and coarse root radii to changes of water supply. In Stokes A (ed) The supporting roots of trees and woody plants: form, function and physiology. Developments in plant and soil sciences. Kluwer, Dordrecht/ Boston/London, pp 227-238

Nadezhdina N, Čermak J (2000c) The technique and instrumentation for estimation the sap flow rate in plants (in Czech). Patent No. 286438 (PV-1587-98)

Nadezhdina N, Cermak J, Nadezhdin V (1998) Heat field deformation method for sap flow measurements. In Cermak J, Nadezhdina N (eds) Measuring sap flow in intact plants. Proc 4th Int Workshop, Zidlochovice, Czech Republic, IUFRO Publications, Brno, pp 72-92

Nadezhdina N, Cermak J, Ceulemans R (2002) Radial patterns of sap flow in woody stems of dominant and understory species: scaling errors associated with positioning of sensors. Tree Physiol 22:907-918

Nadezhdina N, Cermak J (2003) Instrumental methods for studies of structure and function of root systems in large trees. J Exp Bot 54:1511-1521

Nadezhdina N, Tributsch H, Cermak J (2004) Infra-red images of heat field around a linear heater and sap flow in stems of lime trees under natural and experimental conditions. Ann For Sci 61:203-214 
Nadezhdina N, Cermak J, Gasparek J, Nadezhdin V, Prax A (2006) Vertical and horizontal water redistribution within Norway spruce (Picea abies) roots in the Moravian Upland. Tree Physiol 26:1277-1288

Nadezhdina N, Nadezhdin V, Ferreira MI, Pitacco A (2007) Variability with xylem depth in sap flow in trunks and branches of mature olive trees. Tree Physiol 27:105-113

Oliveira RS, Dawson TE, Burgess SSO, Nepstad D (2005) Hydraulic redistribution in three amazonian trees. Oecologia 145:354-363

Pate JS, Jeschke WD, Aylward MJ (1995) Hydraulic architecture and xylem structure of the dimorphic root systems of southwest Australian species of Proteaceae. J Exp Bot 46:907-915

Ribeiro F, Tomé M (2002) Cork weight prediction at tree level. For Ecol Managem 171:231-241

Richards JH, Caldwell MM (1987) Hydraulic lift: substantial nocturnal water transport between soil layers by Artemisia tridentata roots. Oecologia 73:486-489

Ryel RJ, Caldwell MM, Yoder CK, Or D, Leffler AJ (2002) Hydraulic redistribution in a stand of Artemisia tridentate: evaluation of benefits to transpiration assessed with a simulation model. Oecologia 130:173-184
Sakuratani T (1981) A heat balance method for measuring water flux in the stem of intact plants. J Agric Meteorol (Japan) 37:9-17

Scholz FG, Bucci SJ, Goldstein G, Meinzer FC, Franco AC (2002) Hydraulic redistribution of soil water by neotropical savanna trees. Tree Physiol 22:603-612

Schulze ED, Caldwell MM, Canadell J, Mooney HA, Jackson RB, Parson D, Scholes R, Sala OE, Trimborn P (1998) Downward flux of water through roots (i.e. inverse hydraulic lift) in dry Kalahari sands. Oecologia 115:460-462

Smith DM, Jackson NA, Roberts JM, Ong CK (1999) Reverse flow of sap in tree roots and downward siphoning of water by Grevillia robusta. Funct Ecol 13:256-264

Tavares AG, Oliveira O (2001) Analysis of geological and hydrogeological Conditions of an area S and SE of Rio Frio. Technical note WATERUSE project. IDRHa, Lisbon

Warren JM, Meinzer FC, Brooks JR, Domec JC (2005) Vertical stratification of soil water storage and release dynamics in Pacific northwest coniferous forests. Agric For Meterolog 130:39-58 